\title{
LA PARADOJA DE LOS MOVIMIENTOS INDÍGENAS EN BOLIVIA (1990-2008)
}

\section{THE PARADOX OF INDIGENOUS MOVEMENTS IN BOLIVIA (1990-2008)}

\author{
Edwin Cruz Rodríguez*
}

\begin{abstract}
Resumen
Entre 1990 y 2008, los movimientos indígenas bolivianos se caracterizaron por la fragmentación a nivel organizativo y discursivo. Sin embargo, pese a esa condición, consiguieron impactos institucionales relevantes como el reconocimiento de derechos colectivos en las reformas constitucionales de $1994 \mathrm{y}$ 2009. Este artículo ofrece una explicación a esta paradoja. La fragmentación se explica porque la estructura de oportunidad política (EOP) generó incentivos para que los movimientos privilegiaran en un primer momento el repertorio institucional-electoral. La «democracia pactada» ofreció incentivos para la participación institucional de los movimientos indígenas, mientras una tradición de represión aumentaba los costos para la acción colectiva de protesta. Ello tuvo consecuencias paradójicas: al mismo tiempo provocó la competencia electoral entre fracciones del movimiento katarista y permitió el establecimiento de alianzas con las élites gubernamentales del MNR para llevar a cabo las reformas de 1994. Por otra parte, los cambios en las EOP con el derrumbe de la «democracia pactada» alentaron la protesta pese a los costos en términos de represión, entre 2000 y 2005. Aunque los movimientos no pudieron generar una articulación estable y orgánica, no todo se explica por las oportunidades y constricciones estructurales, sino también por la agencia de los indígenas. Los movimientos supieron aprovechar oportunidades políticas en coyunturas particulares combinando distintos repertorios, estableciendo alianzas con actores influyentes y creando sus propias oportunidades.
\end{abstract}

Palabras clave: Movimientos indígenas, Bolivia, fragmentación, impacto institucional.

\begin{abstract}
Between 1990 and 2008, Bolivia's indigenous movements were characterized by fragmentation at the organizational and discursive level. However, despite this condition, they achieved relevant institutional impacts, such as the recognition of collective rights in the constitutional reforms of 1994 and 2009. This article provides an explanation for this paradox. Fragmentation can be explained because the structure of political opportunity (EOP) created incentives for movements to give privilege, at first to the institucionalelectoral repertoire. The "Agreed democracy" offered incentives for institutional participation of the indigenous movements, while a tradition of repression increased the costs of collective action of protest. This had paradoxical consequences: at the same time caused the electoral competition between fractions of the Katarista movement and allowed the establishment of partnerships with government elites of the MNR to carry out the reforms of 1994. On the other hand, changes in the EOP with the collapse of the "pacted democracy" encouraged the protest despite the costs in terms of repression, between 2000 and 2005. Although the movement failed to generate stable and organic articulation, not everything can be
\end{abstract}

Artículo recibido: 15/05/2013 Aprobado: 12/06/2013

* Magister en análisis de problemas políticos, económicos e internacionales. Estudiante de doctorado en estudios políticos. Email: ecruzr@unal.edu.co 
explained by structural opportunities and constraints, but also by the agency of the indigenous. The movements took advantage of political opportunities in particular situations combining different repertoires, establishing partnerships with influential actors and creating their own opportunities.

Key words: indigenous movements, Bolivia, fragmentation, institutional impact.

\section{Exordio}

En agosto de 1990, miles de mujeres y hombres indígenas partieron del Oriente hacia La Paz, a fin de hacer oír sus demandas por territorio, en lo que denominaron la «Marcha por el territorio y la dignidad». El entonces presidente Jaime Paz Zamora, al encontrarse con ellos, declaró: «antes conocíamos sólo la cultura aymara y quechua (...) ahora conocemos a los pueblos indígenas del Beni, Santa Cruz, Chuquisaca y Tarija» (Arias y Molina 1997, 68). De esa manera, no solo fechó el descubrimiento de los pueblos originarios del Oriente, 500 años después del descubrimiento de América, también selló el inicio de un período de intensas luchas indígenas cuyo impacto más relevante ha sido el reconocimiento del Estado plurinacional en la Constitución de 2009.

Las marchas indígenas del Oriente se repetirían en otras oportunidades $(1996,2000,2002)$ demandando su derecho al territorio. Sin embargo, tales acciones no fueron suficientes para conseguir una articulación estable con los movimientos indígenas del Altiplano, aunque en 1995 y 1997 se desarrollaron dos congresos conjuntos bajo auspicio de la Confederación Sindical Única de Trabajadores Campesinos de Bolivia (CSUTCB), denominados «Tierra, territorio e instrumento político». Las organizaciones del Altiplano se habían volcado a un repertorio de acción colectiva institucional que les había permitido, no sin tensiones, tener el primer vicepresidente indígena de la historia, en 1993, e impulsar una reforma constitucional que, entre otras cosas, reconoció valiosos derechos colectivos a los pueblos indígenas y declaró el país como multiétnico y pluricultural.

Una articulación parcial solo sería posible en 2004, cuando las principales organizaciones indígenas y sociales deciden unirse en torno al proyecto de construcción del Estado plurinacional, de cara a la Asamblea Constituyente, en el «Pacto de Unidad». El proceso constituyente tuvo lugar en el gobierno del primer presidente indígena en la historia boliviana, Evo Morales (2007), y estuvo caracterizado por la beligerancia entre sus partidarios y sus opositores, las élites del Oriente, lo que contribuyó a man- tener la articulación entre sectores indígenas (Zalles 2008, Zuazo 2010). Sin embargo, pese a la ampliación de derechos que supuso la nueva Constitución (2009) y el reconocimiento de la plurinacionalidad, la fragmentación retornó una vez que el gobierno se consolidó (VVAA 2010).

Este panorama plantea una interesante paradoja: pese a la fragmentación, e incluso las disputas internas, los movimientos consiguieron importantes reformas orientadas al reconocimiento de sus derechos colectivos en distintos momentos. ¿Qué explica la fragmentación de los movimientos indígenas bolivianos?, ¿por qué, pese a esa fragmentación, han tenido un impacto institucional importante?

Este artículo intenta responder a estas preguntas. Argumenta que la fragmentación se produce a nivel organizativo y discursivo, y se explica porque la estructura de oportunidades políticas, caracterizada por apertura institucional más represión de la protesta, hizo que los movimientos privilegiaran inicialmente un repertorio de acción basado en la acción institucional y electoral, lo cual indujo a la competencia entre distintas fracciones del movimiento. No obstante, los movimientos consiguieron importantes reformas al aprovechar oportunidades políticas en coyunturas particulares combinando distintos repertorios, estableciendo alianzas con actores influyentes y creando sus propias oportunidades. En otras palabras, la apertura institucional de la «democracia pactada», acompañada de una tradición de represión de la protesta, tuvo como efecto que los movimientos indígenas privilegiaran una forma de participación institucional, que posibilitó el establecimiento de alianzas de gobierno para poner en práctica las reformas. En el mismo sentido, el derrumbe de la «democracia pactada» y las oportunidades que abrió explican el ciclo de protesta que experimentó Bolivia entre 2000 y 2005 , cuando declinaba la capacidad de protesta del movimiento ecuatoriano.

Para desarrollar este argumento recurriremos a las categorías de análisis provistas por la «agenda clásica» para el estudio de los movimientos sociales (McAdam, Tarrow y Tilly 2005, 45; McAdam, McCarthy y Zald 1999; 
Tarrow 1997). En consecuencia, la primera parte estudia las estructuras de movilización y la fragmentación organizativa de los movimientos; la segunda analiza los marcos de acción colectiva y su segmentación discursiva; la tercera reconstruye la estructura de oportunidad política (EOP) que da origen a los movimientos; y finalmente, se explica la paradoja mencionada examinando las interacciones entre estas variables.

\section{Fraccionamiento organizativo: las estructuras de movilización}

Las estructuras de movilización son «los canales colectivos formales e informales, a través de los cuales la gente puede movilizarse e implicarse en la acción colectiva» (McAdam, Mc-Carthy y Zald 1999, 25). Incluye las formas organizativas y los «núcleos socioestructurales cotidianos de micromovilización», grupos cuya función no es la movilización pero que pueden generarla (familias, redes de amigos, asociaciones, etc.) (McCarthy 1999, 206). En Bolivia estos núcleos corresponden a las comunidades indígenas, que adoptan formas disímiles dependiendo de la región y han sido apoyadas por iglesias protestantes y ONGs.

En el Oriente boliviano, con la reforma agraria de 1953 los «grupos selvícolas» quedarían protegidos por el Estado y su propiedad sería inalienable, pero nunca se fijaron criterios y sus tierras fueron tituladas a terceros. Los pueblos indígenas fueron perdiendo el control del espacio por el avance de la economía nacional, la ganadería y las obras de infraestructura, la explotación de recursos naturales y la colonización (Balza 2001, 29). Algunas comunidades fueron absorbidas como pobres en las urbes y otras demandaron del Estado el reconocimiento de un territorio propio. La expansión de colonizadores y actividades agroindustriales, coincidentes con el apoyo de ONGs, explican el surgimiento del movimiento. Por ejemplo, la ONG Ayuda Para el Campesinado Boliviano (APCOB) tuvo un gran influjo sobre la Confederación Indígena del Oriente Boliviano (CIDOB), que adoptó una forma federativa sobre la base de las comunidades y pueblos (Hirsch 2003, 88).

Si bien en el Altiplano boliviano los movimientos también reivindican la organización con base en comunidades, se trata de procesos diversos. De acuerdo con McCarthly $(1999,215)$, hay una disponibilidad de formas organizativas en cada cultura sobre la que los movimientos adaptan, innovan e inventan. Así, en el Altiplano existe una fusión entre las comunidades 0 ayllus, que se negaron a desaparecer con las reformas agrarias del siglo XIX, y los sindicatos agrarios, a partir de la reforma agraria de 1953. En ese entonces, los Comandos Rurales del Movimiento Nacionalista Revolucionario (MNR) constituyeron la base de la reforma, organizaron los primeros sindicatos agrarios, basados en la experiencia de los mineros, articulados clientelarmente al partido. La reforma fortaleció la sindicalización porque daba posesión provisional de las tierras que los campesinos tuvieran en usufructo, mientras se procedía a la afectación legal de las haciendas, siempre y cuando constituyeran un sindicato (Pearse, 1986, 348). En regiones donde persistía el ayllu, este se ajustó al sindicato conservando cierta autonomía (Albó, $1990,362)^{1}$.

Desde la perspectiva de las estructuras de movilización, hubo una fragmentación en los movimientos bolivianos, impidiendo una mejor coordinación con acciones de mayor alcance. Las organizaciones indígenas emprendieron procesos hacia la unidad a nivel nacional, a fines de los 70s y principios de los 80s, con la formación de la Confederación Sindical Única de Trabajadores Campesinos de Bolivia (CSUTCB), en 1979. Sin embargo, las tendencias hacia la fragmentación persistieron, en buena parte porque distintas facciones del movimiento katarista ingresaron a la arena electoral (Calla 1993).

Los movimientos indígenas bolivianos no pudieron consolidar un nivel de articulación o al menos coordinación nacional. Aunque este rol pudo desempeñarlo la CSUTCB, a principios de los 80s, las dinámicas de los movimientos se caracterizaron por la fragmentación entre las iniciativas del Altiplano y del Oriente, y el faccionalismo alentado por liderazgos personalistas que persiste incluso luego del arribo de Evo Morales al poder en 2006 .

En el período estudiado, hubo varios procesos organizativos en Bolivia. En Al altiplano el primer proceso estuvo representado por la CSUTCB, heredera del sindicalismo agrario, pero fundada con orientación étnica en 1979. Se caracterizó por tener un funcionamiento

1. En zonas donde predominaba la hacienda, como Cochabamba, los sindicatos sustituyeron las organizaciones tradicionales. En el Altiplano, se fusionaron ambiguamente con los ayllus y todo miembro de la comunidad pasó automáticamente a ser miembro de un sindicato (Albó 1986, 416). 
«cupular» y pocas relaciones con sus bases (Ticona 2005, 147). Tuvo gran representatividad en los 80 s y parte de los 90s, pero no consiguió una articulación del movimiento similar a la conseguida por la CONAIE. Sin embargo, en los últimos lustros funcionó como un espacio de encuentro entre distintas tendencias del movimiento, como los cocaleros y sectores aymaras representados por el histórico líder Felipe Quispe, entre otros.

La representatividad de la CSUTCB fue fuertemente cuestionada por el movimiento de reconstrucción del ayllu, en regiones del Altiplano donde las comunidades se resistieron a desaparecer. Se desarrolló desde mediados de los 80s en contraposición al sindicalismo campesino de la CSUTCB, al considerarlo como una imposición del colonialismo. Fue apoyado por ONGs y proyectos de desarrollo (Andolina et. al. 2005, 145). Aspira a reconstruir las formas y espacios de gobierno precoloniales y la democracia comunitaria, organizado en federaciones de ayllus, markas y suyus (territorialidades político administrativas precoloniales). La organización representativa a nivel nacional es el Consejo Nacional de Ayllus y Markas del Qollasuyo (CONAMAQ), fundado en marzo de 1997.

Hubo además tendencias minoritarias que incursionaron entre los movimientos o en ámbitos electorales en distintos momentos. Una tendencia importante fue la del radicalismo aymara, que proviene del indianismo de los 70s, aparece a fines de los 80s y principios de los 90s como guerrilla ${ }^{2}$ y luego en distintas coyunturas como movimiento político electoral. A partir de 1998 esta tendencia estuvo representada por el entonces Secretario Ejecutivo de la CSUTCB, Felipe Quispe, quien jugó un papel importante en el desarrollo de acciones colectivas en los segundos gobiernos de Bánzer (1997-2001) y Sánchez de Lozada (2002-2003), y en 2000 fundó el partido Movimiento Indígena Pachakuti (MIP).

En los valles, el movimiento cocalero se organizó en confederaciones sindicales desde principios de los $80 \mathrm{~s}$ y fue protagónico en los 90s en el interior de la CSUTCB, gracias a su peso numérico (Do Alto 2008, 27). Aunque no se definió como un movimiento indígena sino como un movimiento campesino de productores de coca, poco a poco articuló elementos indígenas con el fin de defender la coca como «hoja sagrada» en un proceso de «etnización» (Sanz 2005, 32). Los cocaleros se convirtieron en el principal articulador del movimiento indígena y de otros sectores populares en la segunda mitad de los 90s, alrededor del «instrumento político», organización fundada por su iniciativa con otras organizaciones sociales e indígenas, primero en la Asamblea por la Soberanía de los Pueblos (APS) (1996), y más tarde en el Instrumento Político por la Soberanía de los Pueblos (IPSP) (1998), que participó en elecciones con la inscripción del Movimiento Al Socialismo (MAS).

Finalmente, los pueblos indígenas del Oriente empezaron a organizarse a principios de los 80 s reunidos en la Confederación Indígena del Oriente Boliviano (CIDOB), fundada en 1982, que agrupa varias organizaciones (Pessoa 1998, 175). Al igual que el CONAMAQ, la CIDOB se desarrolló en estrecha relación con ONGs, principalmente en defensa del territorio frente a compañías madereras y agroindustriales. Fue el movimiento más activo en cuanto a la realización de acciones colectivas de envergadura, pues realizó las marchas de 1990, 1996, 2000 y 2002, con miles de indígenas hacia la sede de gobierno en La Paz.

Entre los movimientos indígenas bolivianos se produjeron varias tensiones que minaron las posibilidades de articulación organizativa. Primero, un clivaje regional y étnico, pues los movimientos del Oriente no pudieron coordinar del todo con los del Altiplano, pese a que su reivindicación territorial fue apoyada por la CSUTCB en dos congresos, denominados «Tierra, territorio e instrumento político», en 1995 y 1997. Segundo, en el Altiplano hubo un conflicto entre el movimiento de reconstrucción del ayllu que disputó las bases sociales de la CSUTCB, acusando el sindicalismo campesino de ser una imposición más del colonialismo y proclamándose representante verdadero de los indígenas (Andolina et. al. 2005, 155). Tercero, fueron permanentes las pugnas entre liderazgos personalistas, algunas veces por el establecimiento de alianzas con actores no indígenas o la participación en el

2. Entre 1989 y 1994 surgen organizaciones armadas con un discurso étnico que reivindican la autodeterminación de las naciones originarias: Las Fuerzas Armadas de Liberación Zárate Willka (FAL-ZW) y el Ejército Guerrillero Tupac katari (EGTK). Este último atentó contra un diplomático estadounidense y explotó torres de alta tensión, tenía sus bases en círculos universitarios y barrios marginales de La Paz. Sin embargo, no prosperaron porque eran grupos urbanos y de clase media que despertaban la suspicacia del campesinado, carecieron de la capacidad articulatoria de los nuevos populismos como los de CONDEPA y Max Fernández, y la persistencia de la comunidad aymara impidió la penetración de Sendero Luminoso pese a que algunos de los miembros de estos grupos mantuvieron contacto con esa guerrilla (Arias y Molina 1997, 71-72). 
gobierno de sectores que se apartaron de las orientaciones de los movimientos ${ }^{3}$.

La fragmentación organizativa se complementó con una segmentación a nivel del marco de acción colectiva, pues aunque todas las demandas podían enmarcarse bajo el Estado plurinacional, en la práctica cada organización o sector se fue por su lado.

\section{Segmentación discursiva: los marcos de acción colectiva}

Los marcos de acción colectiva son «significados compartidos que impulsan a las personas a la acción colectiva» (Tarrow 1997, 57). Para Snow y Benford (1992, 137) designan «esquemas interpretativos» mediante los cuales los participantes en un movimiento social conciben y explican el mundo. Esta categoría resalta la importancia de la cultura en los procesos de movilización, pues parte de una epistemología constructivista donde los significados son construidos socialmente y los intereses materiales no se traducen por sí mismos en guías para la acción (Tarrow 1999, 209). Además, presta atención al papel activo de los actores pues «tanto la cultura como el proceso enmarcador de ideas se conciben estratégicamente» (Zald 1999, 369)4.

Los marcos tienen como propósito «forjar formas compartidas de considerar el mundo y a sí mismos que legitimen y muevan a la acción colectiva» (McAdam, McCarthy y Zald 1999, 27). Los procesos de enmarcado implican un conflicto entre distintas visiones del mundo, formas de explicar los problemas, soluciones y cursos de acción. Esta disputa tiene lugar tanto en el interior de los movimientos como en su ámbito externo, al ser cuestionados por espectadores, funcionarios estatales o contramovimientos (Zald 1999, 370; Rivas 1998, 207). Examinar un marco de acción colectiva implica identificar: 1) el diagnóstico de la realidad, porqué las cosas no son como deberían ser, 2) la identidad, o la autodefinición de un «nosotros», que están de acuerdo con 3) una solución a los problemas, un deber ser en función del cual se produce la acción colectiva.

Los movimientos indígenas bolivianos no pudieron consolidar un nivel de articulación discursiva mediante el marco de acción del estado plurinacional, que les permitiese generar acciones de alto impacto y con un objetivo de largo plazo. La desarticulación organizativa se tradujo en desarticulación discursiva. La demanda del Estado plurinacional pudo haber articulado tempranamente las reivindicaciones de todos los movimientos, pero en la práctica hubo una dispersión de demandas que no lograron articularse del todo en un proyecto común y cada una de las organizaciones planteó demandas en sus propios términos. Veamos:

a. El diagnóstico: para los movimientos el problema principal radica en la persistencia del colonialismo, la opresión y explotación de los pueblos indígenas, y el desconocimiento de su diferencia e identidad ${ }^{5}$. Para ellos, la República no puso fin al colonialismo. Por el contrario, tanto el régimen colonial como el republicano son

3. Por ejemplo, en 1998 la ASP se dividió por un conflicto entre el quechua Alejo Véliz y el aymara Evo Morales. Véliz acusó a su contraparte de alentar el voto cruzado en su contra y a favor del MNR, durante las elecciones de 1997, para privarlo de una curul como diputado (Stefanoni y Do Alto 2006, 55). En las protestas de abril y septiembre de 2000 hubo disputas por el liderazgo del movimiento entre Felipe Quispe y Evo Morales. Quispe habría usado los conflictos para fortalecer su liderazgo fundado en el carisma. El gobierno privilegió las negociaciones con él aumentando su popularidad y dejando de lado a Morales. Quispe no apoyó a este último, pese a que ambos son aymara, por lo que otros sectores cuestionaron su representatividad (Albó 2004, 471-474).

4. Rivas distingue entre procesos de enmarcamiento y marcos de la siguiente forma: «Por «procesos de enmarcamiento» entendemos los esfuerzos estratégicos conscientes realizados por grupos de personas para construir interpretaciones compartidas del mundo y de sí mismos que legitiman y motivan la acción colectiva» (Rivas 1998, 206). «Por marco de acción colectiva entendemos el conjunto de creencias y significados orientados a la acción que inspiran y legitiman las actividades y campañas de los mismos movimientos sociales, dan sentido al mundo social de los participantes en ellos y los ayudan a conformar sus propias identidades personales y colectivas. Esta construcción es necesaria para la aparición de los movimientos, ya que los problemas por sí solos no producen movimientos sociales; requieren una interpretación, la cual es más fácil que tenga lugar donde ya hay sentido, como una iglesia o un grupo constituido». (Rivas 1998, 207).

5. Así por ejemplo, uno de los documentos fundacionales de los movimientos bolivianos, el Manifiesto de Tiwanaku (julio de 1973), afirma: «Nosotros, los campesinos quechuas y aymaras lo mismo que los de otras culturas autóctonas del país... Nos sentimos económicamente explotados y cultural y políticamente oprimidos. En Bolivia no ha habido una integración de culturas sino una superposición y dominación, habiendo permanecido nosotros en el estrato más bajo y explotado de esa pirámide... Pensamos que sin un cambio radical en este aspecto será totalmente imposible crear la unidad nacional y un desarrollo económico dinámico, armónico, propio y adecuado a nuestra realidad y necesidades» (Rivera 1986, 177). Si bien aquí citamos los documentos fundacionales de los movimientos, estos discursos son persistentes en sus acciones colectivas y en coyunturas críticas hasta la actualidad. Ver por ejemplo VVAA (2010) 
percibidos como corruptores del orden social indígena. Ese orden precolonial es concebido en términos de otro tipo de civilización armoniosa, contraria al despojo y la barbarie que trae consigo la Conquista 6 . Esta interpretación de la realidad entre los 70s y 80s, en el ascenso de los movimientos kataristas e indianistas, pero estará presente durante todo el período estudiado.

b. El «nosotros»: En sus discursos, los líderes de los movimientos indígenas se identificaron como pueblos, nacionalidades 0 naciones originarias, y de esa manera cuestionaron las representaciones negativas y racializadas con las que habían sido concebidos como salvajes e incivilizados (Ibarra 1999, 77). Así mismo, estas categorías desafían la de «campesino» con la que el Estado tradicionalmente los había representado. No obstante, existe un debate entre los movimientos sobre la denominación más idónea. Ciertos sectores rechazan los términos indio e indígena como legados de la dominación colonial y prefieren las denominaciones de pueblos o naciones originarias (Albó 1998, 14). Los indígenas del Oriente son más proclives a denominarse como pueblos indígenas 0 indios, mientras que los andinos prefieren la denominación de aymaras, quechuas u originarios (Albó 1996, 332). Las organizaciones se han apropiado en forma diferenciada de la categoría de «nación». Entre las organizaciones del Altiplano existe un traslapamiento entre las etiquetas de naciones originarias y pueblos. Incluso los intentos de articular distintas organizaciones han recurrido a la identificación como pueblos, en la Asamblea por la Soberanía de los Pueblos (1996) o el Instrumento Político por la Soberanía de los Pueblos (1998).

Por otro lado, el «nosotros» que construyen los movimientos no se agota en los indígenas, sino que trata de articular otros actores a sus luchas a partir de la definición de objetivos y enemigos comunes. Esto es lo que se conoció como la «teoría de los dos ojos». El líder aymara Víctor Hugo Cárdenas habría afirmado, en el segundo congreso de la CSUTCB (1983): «hay que ver la realidad con dos ojos: como campesinos explotados, junto con todos los explotados, y como pueblos oprimidos, junto con todos los pueblos oprimidos» (Albó 1996, 327)?.

c. Deber ser o proyecto: El proyecto articulador de los movimientos fue el de construir un Estado plurinacional. Esta categoría apareció por primera vez en Bolivia en la Tesis Política de la CSUTCB (1983) ${ }^{8}$. Designaba una transformación en la manera como se había producido la integración del indio a la nación y la necesidad de reconocer la existencia de distintas naciones indígenas ${ }^{9}$. Sin embargo, no se desarrolló posteriormente $y$, si bien no perdió presencia en el debate público, no se constituyó en la categoría articuladora de su discurso. En el período estudiado, todos los movimientos tenían reivindicaciones que podrían enmarcarse bajo el concepto de Estado plurinacional (la demanda por el reconocimiento de formas tradicionales de gobierno, la «democracia comunitaria», el reconocimiento de derechos colectivos y autonomías territoriales, formas de desarrollo alternativo, etc.). Empero, cada organización planteó sus reivindicaciones en distintos términos sin conseguir una articulación discursiva.

El concepto de Estado plurinacional estuvo presente sobre todo entre las organizaciones del Altiplano. Las organizaciones del Oriente, identificadas como organizaciones de «pueblos indígenas» no articularon en sus plataformas discursivas las categorías de nación y Estado plurinacional y tendieron a enmarcar sus demandas con los conceptos de territorio y autonomía. En el altipla-

6. La Tesis política de la CSUTCB (1983) afirmaba: «Antes de la llegada de los españoles éramos pueblos comunitarios. En nuestra tierra no se conocía el hambre, el lobo, la mentira (...) Todo este desarrollo autónomo fue violentamente interrumpido con la invasión española de 1492. A partir de ese entonces hemos sido degradados a la condición de colonizados, bajo el nombre genérico de indios. Con ello hemos sido despojados de la soberanía sobre nuestros territorios, e incluso, se nos ha negado nuestra dignidad de seres humanos» (Rivera 1986, 202).

7. En la Tesis Política de junio de 1983 llaman a la unión de todos los oprimidos: «Durante toda esta trayectoria de lucha vimos que nuestro movimiento sindical formaba parte de una lucha más amplia de todos los oprimidos de Bolivia. Constatamos que con los hermanos mineros, fabriles, constructores, no solamente nos unen relaciones de solidaridad de clase, sino también raíces históricas y culturales comunes, y la lucha contra los mismos enemigos» (Rivera 1986, 206).

8. «Queremos ser libres en una sociedad sin explotación ni opresión organizada en un Estado plurinacional que desarrolle nuestras culturas y auténticas formas de autogobierno propio» (Rivera 1986, 199).

9. «Debemos decir basta a una falsa integración y homogeneización cultural que pretende despersonalizarnos a través de la castellanización forzosa, la aculturación y la alienación. La CSUTCB debe convertirse en expresión cada vez más fiel y unitaria de esta diversidad... Nuestra lucha tendrá que orientarse a que esta diversidad se exprese en todos los ámbitos de la vida nacional. Porque no queremos parches ni reformas parciales, queremos una liberación definitiva y la construcción de una sociedad plurinacional y pluricultural que, manteniendo la unidad del Estado, combine y desarrolle la diversidad de naciones aymara, quechua, tupiguaraní, ayoreode y todas las que la integran. No puede haber una verdadera liberación si no se respeta la diversidad plurinacional de nuestro país y las diversas formas de autogobierno de nuestros pueblos» (Rivera 1986, 211). 
no las organizaciones han reivindicado con más vehemencia estas categorías. Al igual que la CSUTCB, el CONAMAQ ha reivindicado la construcción de un Estado plurinacional. Sin embargo, tendió a articular sus demandas planteando sobre todo el reconocimiento de las territorialidades precoloniales (ayllus, markas, suyus) con estatus de municipios (Arnold y Spedding 2007, 178). Además, el radicalismo aymara, representado entre otros por Felipe Quispe y su partido, el Movimiento Indígena Pachakuti (MIP), tendió a apartarse del marco del Estado plurinacional al plantear la autodeterminación de las naciones originarias ${ }^{10}$.

En parte, esta desarticulación discursiva se explica por la fragmentación organizativa que caracterizó los movimientos en Bolivia. Sólo muy recientemente, en octubre de 2004, con el «Pacto de Unidad» que reunió organizaciones indígenas y de otros sectores con el objeto de definir una propuesta conjunta para la convocatoria a la Asamblea Constituyente, distintas demandas se enmarcaron en el proyecto del Estado plurinacional (Orellana 2005, 69) $)^{11}$

\section{Las oportunidades políticas en el origen de los movimientos}

Como afirma Tarrow $(1997,49)$, «los movimientos sociales se forman cuando los ciudadanos corrientes, a veces animados por líderes, responden a cambios en las oportunidades que reducen los costes de la acción colectiva, descubren aliados potenciales y muestran en qué son vulnerables las élites y las autoridades» ${ }^{12}$. La estructura de oportunidades políticas (EOP) designa las dimensiones del entorno político que fomentan o desincentivan la acción colectiva. comprende la estructura política institucional y las relaciones informales de poder de un sistema político nacional, y se usa como una variable 0 una serie de variables independientes para explicar el origen, la forma 0 incluso el impacto alcanzado por los movimientos (McAdam, McCarthy y Zald 1999, 23).

El concepto no ha estado exento de la crítica. Existe un problema con su amplitud, pues hace referencia a cualquier dimensión del contexto que actúe sobre los movimientos y, al incluir tantas variables, corre el riesgo de no explicar nada (Gamson y Meyer 1999, 389; della Porta 1999,102$)$. Por eso que se haya tratado de puntualizar las variables pertinentes ${ }^{13}$. En fin, ello implica que es necesario hacer explícita la variable dependiente a explicar y la dimensión concreta de la EOP que la explica (McAdam 1999, 59).

McAdam (1999, 62-64) llama la atención sobre la necesidad de contemplar el contexto internacional dentro de la EOP. Esta variable también contribuye a explicar la emergencia de los movimientos indígenas (Martí, 2010).

10. Aunque el discurso de Quispe es ambiguo, en el límite propone el desconocimiento de la nación y el Estado Bolivianos para reconstruir el Qollasuyo. De ahí que algunos autores han llegado a sostener que «potencialmente el MIP puede convertirse en una fuerza separatista» (De la Fuente 2002, 87).

11. Una propuesta inicial de las organizaciones planteó la existencia de 16 naciones originarias en territorio boliviano y una reorganización territorial del Estado en función de sus autonomías. El Pacto fue suscrito por el CONAMAQ, la CIDOB, la Confederación Sindical de Colonizadores de Bolivia (CSCB), la CSUTCB, la Federación Nacional de Mujeres Campesinas Indígenas Originarias de Bolivia Bartolina Sisa (FNMCIOB BS), el Movimiento Cultural Afrodescendiente, la Asociación Nacional de Regantes y Sistemas Comunitarios de Agua Potable, y la Coordinadora de Pueblos Étnicos de Santa Cruz. No lo suscribió la CONNIOB (Confederación Nacional de Naciones Indígenas Originarias de Bolivia), organización fundada el 28 de diciembre de 2000, que se declara representante de 36 naciones originarias en Bolivia, dado que en esta coyuntura se alineó con las propuestas de las élites regionales del oriente y los Comités Cívicos en torno al referéndum sobre autonomías.

12. Esta definición es bastante «estructuralista», dado que supone que las oportunidades son factores objetivos del contexto. Sin embargo, en otros textos el autor hace énfasis en la interpretación de las oportunidades por parte de los actores. por ejemplo: «Cuando hablo de oportunidad política estoy haciendo referencia a señales continuas -aunque no necesariamente permanentes, formales o a nivel nacional- percibidas por los agentes sociales o politicos que les animan o desaniman a utilizar los recursos con los que cuentan para crear movimientos sociales. Según mi concepto de la oportunidad política habría pues que considerar, no solo las estructuras formales, como las instituciones, sino también las estructuras de alianza generadas por los conflictos, que contribuyen a la obtención de recursos y crean una red de oposición frente a constricciones o limitaciones externas al grupo» (Tarrow 1999, 89). Para algunos autores el proceso de interpretación por parte de los actores es esencial: «cuando no se reconoce la oportunidad es como si no existiera. La oportunidad política implica la percepción de una posibilidad de cambio, es decir, tiene un componente que es, básicamente, un «constructo» social. Los elementos más estables de la oportunidad política delimitan el ámbito en el que toda una serie de actores luchan por definir las oportunidades» (Gamson y Meyer 1999, 401).

13. Para Tarrow $(1999,90)$, «existen cuatro tipos de indicadores importantes: la posibilidad de acceder al poder, los cambios en las alineaciones, la posibilidad de contar con aliados influyentes y las escisiones en el seno de las élites». McAdam (1999, 54-55), por su lado, sostiene que serían parte de la EOP: «1. El grado de apertura relativa del sistema político institucionalizado. 2. La estabilidad o inestabilidad de las alineaciones entre élites, alineaciones que ejercen una gran influencia en el ámbito de lo político. 3. La presencia o ausencia de aliados entre las élites. 4. Capacidad del Estado y su propensión a la represión». 
El fin de la guerra fría posibilitó la emergencia de discursos distintos a su dicotomía y una «internacionalización» de la cuestión indígena, con preocupaciones como el medio ambiente, los derechos humanos y el desarrollo sostenible 0 etnodesarrollo (Gros 1999, 8). Los organismos internacionales de desarrollo (Banco Mundial, BID, PNUD) incorporaron en sus agendas el tema indígena y crearon instancias especializadas (García 2003, 199). Articulado con las políticas ambientales, el indígena se valoró como protector «natural» del medio ambiente (Gros 2000, 358).

Los movimientos indígenas bolivianos se desarrollan en el contexto de democratización, a fines de los 70s y principios de los $80 \mathrm{~s}$, y reestructuración del Estado en los 90s. Este contexto abre mayores posibilidades para organizarse y participar.

El tránsito del Estado desarrollista al neoliberal tiene un gran impacto en el desarrollo de los movimientos. En el contexto de la crisis económica de los años ochenta, que afecta críticamente al sector agrario, el retiro de las políticas del estado interventor generan descontentos que provocan la politización de las comunidades indígenas campesinas. Además, con el modelo de desarrollo centrado en el Estado entran en crisis las políticas asimilacionistas y las instituciones encargadas de integrar los indígenas como campesinos (Iglesias y Espasandín 2007, 59). Como consecuencia, los indígenas son liberados de las presiones hacia la asimilación y se abren espacios para plantear proyectos de nación propios, en la clave de demandas por la democracia participativa, la descentralización y la autonomía (Gros 1999, 10). Finalmente, la identificación como indígenas tiene incentivos en las políticas de discriminación positiva y focalización del Estado neoliberal (Bengoa 2000, 68).

Por otra parte, la crisis general que afecta a la izquierda por esta época, en sus discursos y organizaciones, genera un vacío en el campo popular que permite el ascenso de las organizaciones indígenas al escenario nacional. Con la transición a la democracia creció el voto por la izquierda y la Unión Democrática Popular (UDP) llegó al poder (1982-1985). Sin embargo, con el fracaso económico de este gobierno, la izquierda perdió credibilidad y dejó el camino abierto para la implementación del modelo neoliberal (Albó 1996, 329). La Central Obrera Boliviana (COB), determinante en las luchas sociales desde la Revolución de 1952, entró en crisis (Calla 2000, 215). Se opuso a las políticas neoliberales luego de la promulgación del Decreto Supremo 21060 (1985) y fue duramente reprimida con el despido masivo de trabajadores mineros (Basset 2005, 203). El sindicalismo cedió en favor del surgimiento de comités regionales, juntas vecinales, organizaciones de mujeres, movimientos ecologistas y organizaciones indígenas (Sanz 2005, 216), pues continuó operando desde una perspectiva clasista con dificultades para representar las reivindicaciones de estos actores (Calla 1993, 80).

Finalmente, la emergencia de los movimientos en los 90s coincide con un cambio sustancial en las orientaciones del Estado que lo llevan a reconocer la diversidad y abanderar políticas multiculturalistas, dejando un tanto de lado el ideal de una nación homogénea fundada en el mestizaje. Por ejemplo, el presidente boliviano Jaime Paz Zamora (1989-1993) planteó en eventos internacionales el tema indígena, consiguió la sede del Fondo de Desarrollo Indígena, revivió el Instituto Indigenista, apoyó la educación intercultural, dialogó personalmente con los manifestantes en la Marcha por el territorio y la dignidad y ratificó el Convenio 169 de la OIT (Albó 1996, 338).

\section{Explicando la paradoja}

Como sostienen McAdam, McCarthy y Zald (1999, 2629) las tres variables de la agenda clásica, estructuras de movilización, marcos de acción colectiva y estructuras de oportunidades políticas, por separado son necesarias pero no suficientes para explicar las dinámicas de la acción colectiva, es necesario examinar la interacción entre ellas para entender cómo cambian en el tiempo y de esa manera explicar la fragmentación y el impacto institucional de los movimientos indígenas bolivianos. Las EOP cambian con el tiempo de acuerdo a las relaciones entre los distintos actores y tienen un efecto sobre las estructuras de movilización, los repertorios de acción y los marcos de acción colectiva. En el mismo sentido, es posible que distintas formas de organización y procesos de enmarcado sean más eficaces para el aprovechamiento de determinadas oportunidades.

Siguiendo a McAdam, McCarthy y Zald $(1999,33)$, la EOP y los cambios que en ella se operen pueden llegar a determinar la forma de la acción colectiva (movilización, lobbies, elecciones, violencia, etc.). Como afirma Ruch (1999, 271), la estructura del movimiento tiende a ser más formal (partido, grupo de interés), cuando más apertura en el sistema de partidos y en los mecanismos de toma 
de decisiones políticas exista. Así, un aspecto que explica mejor las tempranas reformas bolivianas de 1994 es la diferencia en los repertorios de acción y las formas organizativas que adoptan los movimientos como consecuencia de la EOP. Las oportunidades en Bolivia, apertura institucional acompañada de una tradición de represión de la protesta, tuvieron como efecto que los movimientos indígenas privilegiaran una forma de participación institucional, que al mismo tiempo contribuyó a la fragmentación de los movimientos y posibilitó el establecimiento de alianzas de gobierno para poner en práctica las reformas.

La transición a la democracia fue posible por un acuerdo entre partidos que se renovaba periódicamente conocido como «democracia pactada» (Torrico 2006). Si bien este acuerdo tuvo un carácter excluyente, contribuyó al mantenimiento de un régimen democrático relativamente estable que en sí mismo constituyó una oportunidad al develar la existencia de potenciales aliados y mejorar las condiciones de participación. Este elemento favoreció la puesta en práctica de repertorios de acción institucionales y la temprana incursión a la política electoral de los movimientos indígenas, sobre todo en el Altiplano. Ello podría explicar el hecho de que, con anterioridad a la década de los 90s, solo existieran partidos de corte étnico en Bolivia (Van Cott 2003, 40).

Con la transición a la democracia los movimientos indígenas privilegiaron un repertorio institucional-electoral. Así, distintas facciones del movimiento katarista e indianista participaron desde fines de los 70s en elecciones mediante coaliciones con otros actores (Calla 1993, 68-71), lo cual contribuyó a su fragmentación en tanto provocó la competencia por votos ${ }^{14}$. Más tarde, la participación en la arena electoral entre los movimientos indígenas tiene un gran impulso con un cambio fundamental en la EOP: la apertura con la Ley de Participación Popular (1994) que conjugó la democracia participativa con distintas formas de descentralización (Van Cott 2003, 42).

Este argumento se complementa al estudiar la variable represión en la EOP. Es bien sabido que el nivel de represión tiene gran incidencia en la forma que adoptan los repertorios de acción (della Porta 1999, 102). McAdam $(1999,58)$ sugiere que cuando disminuye la capacidad de represión estatal de la protesta es más factible que emerjan movimientos poco institucionalizados. En Bolivia existe una tradición de represión de la protesta, que eleva los costos de la acción colectiva. Así, los movimientos indígenas bolivianos no solo habrían optado por la participación institucional-electoral para aprovechar las oportunidades de la «democracia pactada», también lo hicieron para evitar ser reprimidos.

En el caso boliviano está presente una tradición de represión de la protesta social que no finalizó del todo con el retorno a la democracia a principios de los 80s, y afloró con fuerza en la revitalización de los movimientos sociales durante los segundos gobiernos de Banzer (1997-2001) y Sánchez de Lozada (2002-2003) ${ }^{15}$. En la memoria de las élites políticas bolivianas está presente la historia de las sublevaciones indígenas y el sentimiento de amenaza permanente de una «guerra de razas» (Rivera 1986, 21). Si a ello se adiciona el hecho de que en Bolivia la población indígena es mayoritaria, se tiene que el menor brote

14. El Movimiento Indio Túpac Katari (MITKA) participó con fuerzas propias. El Movimiento Revolucionario Túpac Katari (MRTK) privilegió una estrategia «frentista» en alianza con otros sectores de izquierda en la UDP. Ingresó a la UDP para las elecciones de 1978 y rompió con ella en enero de 1979, luego se escindió en dos facciones, una de ellas usó la sigla del Movimiento para articularse con el MNR de Víctor Paz en las elecciones de 1979. Jenaro Flores y Víctor Hugo Cárdenas se abstuvieron de participar en esos comicios y llamaron a votar por la izquierda (Calla 1993, 68). Para las elecciones de 1980 Cárdenas y Flores formaron un frente con Juan Lechín, cabeza del Partido Revolucionario de Izquierda Nacionalista (PRIN), y máximo dirigente de la COB. Lechín renunció antes de las elecciones y dejó al MRTK desarticulado electoralmente. Para las elecciones de junio de 1985 los Kataristas se presentaron con la UDP mientras que los indianistas se marginaron del proceso. Por problemas con la sigla del movimiento katarista frente a la autoridad electoral se formó el MRTK-L (Movimiento Revolucionario Túpac Katari de Liberación) con el que participaron Jenaro Flores y Filemón Escobar (Calla 1993, 71).

15. Durante la «Guerra del Agua» en abril de 2000, en Bolivia, el gobierno declaró el estado de sitio, que se prolongó por 13 días durante los cuales las Fuerzas Armadas reprimieron duramente a los manifestantes. En septiembre de 2000 la represión produjo 6 muertos en el Chapare, 4 en el altiplano paceño, 4 en el valle de Cochabamba y 3 en Huarina en un bombardeo aéreo (Cajías 2004, 503). El 15 de enero de 2002, los cocaleros hicieron una marcha en protesta por el cierre del mercado de Sacaba, cerca de Cochabamba, que devino en un enfrentamiento de 4 días entre policías y cocaleros, como resultado del cual quedaron 5 campesinos, 3 soldados y 1 policía muertos, y muchos detenidos (Stefanoni y Do Alto 2006, 64-65). El 12 de febrero de 2003, al descontento con el impuesto del $12,5 \%$ sobre los ingresos de las personas que tuvieran más de dos salarios mínimos, para manejar el déficit fiscal y enfrentar una visita del FMI, se adicionó un motín de la policía exigiendo un incremento en su salario. Hasta el día siguiente se produjeron enfrentamientos entre ejército y policía, y entre ejército y manifestantes, que al final dejaron 33 muertos y 189 heridos (Solón 2003, 25). En las protestas que devinieron en la destitución de Sánchez de Lozada, la «Guerra del gas», en septiembre de 2003, el gobierno desencadenó una gran represión que dejó 67 muertos y más de 400 heridos (Cabezas 2007, 207). 
de descontento es percibido por los gobiernos como una amenaza a la estabilidad del Estado que los lleva a emplear la fuerza.

Así, un repertorio institucional contribuyó a la fragmentación pero simultáneamente permitió a los movimientos bolivianos encontrar aliados entre las élites gobernantes para realizar tempranamente las reformas de reconocimiento de derechos colectivos. Estas reformas estuvieron soportadas en la coalición entre el MNR y el MRTKL para las elecciones presidenciales de $1993^{16}$. El Plan de gobierno se denominó «Plan de todos» y planteó una modernización del país desde el punto de vista del reformismo neoliberal articulado al multiculturalismo. Las principales reformas, la ley del Instituto Nacional de Reforma Agraria (INRA) que permitió cierta autonomía territorial con los Territorios Comunitarios de Origen (TCO), la Ley de Participación Popular que amplió la participación y la descentralización mediante la figura de las Organizaciones Territoriales de Base (OTB), y la reforma Constitucional que reconoció la nación en el artículo 1 como «libre, soberana, multiétnica y pluricultural, constituida en República unitaria» (Vadillo 1996, 30), se llevaron a cabo gracias a la coalición de gobierno en 1994.

Finalmente, la EOP supone un proceso que cambia por la acción agregada de los distintos actores (Tarrow 1999, 91). Los cambios en la EOP permiten explicar por qué, pese a los niveles de represión, en Bolivia tiene lugar un ciclo de protesta entre 2000 y 2005 . Es decir, un cambio en los repertorios que combina la acción institucional con la acción disruptiva. La revitalización de las acciones colectivas de los movimientos bolivianos a partir del 2000 tiene lugar en el contexto de «derrumbe» del modelo de gobernabilidad basado en la «democracia pactada», aunado a las frustraciones que generó el proceso de descentralización y participación ciudadana alentado por la Ley de Participación Popular (Basset 2004, 59). Ese contexto hace que los incentivos para la acción colectiva sean superiores que sus costos en términos de represión. Además, el desgaste del régimen político y de la clase política tradicional llegó a un punto crucial con temas como la exportación del gas por puerto chileno, que despertó el nacionalismo popular y llevó a una completa deslegitimación del régimen y la salida forzada del país de Sánchez de Lozada en septiembre de 2003. Como sostiene Oberschall $(1999,146)$, «la falta de legitimidad de un régimen es una clara oportunidad para los disidentes».

Esto posibilitó una combinación de repertorios de protesta y participación en elecciones en un «ciclo rebelde» entre 2000 y 2005 (Cabezas 2007). En este período los movimientos aprovecharon y crearon nuevas oportunidades (Tarrow 1999, 95-96). Así el MAS-IPSP no solo articuló los sectores indígenas sino también otros sectores descontentos y combinó con éxito la acción institucional con la no institucional (Archondo 2007, 86). En 2002 Evo Morales obtuvo el segundo lugar en las elecciones presidenciales, disputando la elección en el Congreso con Gonzalo Sánchez de Lozada. Tres años más tarde, en las elecciones del 18 de diciembre de 2005, el MAS-IPSP tuvo un triunfo contundente con $53,7 \%$ de los votos válidos para Morales (1.544.374 votos), contra $28,6 \%$ de los votos de su contendiente Jorge Quiroga (821.745 votos) (Do Alto 2008, 26). El triunfo significó una ruptura fundamental porque por primera vez un indígena llegó a la Presidencia de la República y, pese a las tensiones con sectores indígenas y sus demandas, permitió la realización de la Asamblea Constituyente y el reconocimiento del Estado plurinacional.

No obstante, una vez consolidado el gobierno se generaron nuevas tensiones y desarticulaciones. Para los principales líderes de los movimientos altiplánicos, el gobierno de Morales no ha significado un esfuerzo real hacia la descolonización, sino por el contrario ha continuado con las prácticas de exclusión coloniales (VVAA 2010). Por su parte, los movimientos del Oriente, no comparten el modelo de desarrollo del gobierno, basado en el «capitalismo andino-amazónico», porque genera consecuencias per-

16. Inicialmente el líder histórico del katarismo, Víctor Hugo Cárdenas, había discutido con sectores campesinos e indígenas la posibilidad de lanzar una propuesta conjunta de cara a las elecciones presidenciales. Pero también había mantenido buenas relaciones con el MNR, desde 1989, pese a sus duras críticas frente al partido que implementó la Nueva Política Económica y marcó el giro hacia el neoliberalismo. En 1992 el MNR contrató una consulta de opinión sobre posibles candidatos como fórmula vicepresidencial del ex ministro de economía Gonzalo Sánchez de Lozada, de la cual salió favorecido Cárdenas. Él era perfecto para atraer los votos donde el MNR no los tenía como en la Ciudad y en el Departamento de La Paz. Tras el triunfo de la coalición, los dirigentes campesinos que trabajaron previamente en la propuesta de Cárdenas quedaron «descolocados», unos lo tildaron de traidor y otros se alegraron de que un aymara llegara al poder (Albó 1996, 338). Cárdenas, por su parte, justificó su decisión afirmando: «el marginamiento, la desigualdad y la discriminación disminuirán en Bolivia, para construir un país pluricultural, pluriétnico y plurinacional» (Albó 1996, 339-340). 
versas sobre el medio ambiente y particularmente sobre sus territorios. Esta tensión se ha manifestado con fuerza desde 2011 con la construcción de una carretera en el Amazonas en el Territorio Indígena del Parque Nacional Isidoro Sécure (TIPNIS).

\section{Conclusión}

Durante las dos últimas décadas, los movimientos indígenas bolivianos se caracterizaron por la fragmentación en términos organizativos y discursivos. Sin embargo, esa fragmentación no ha sido obstáculo para conseguir un importante impacto institucional, con las reformas constitucionales de 1994 y 2009, que reconocieron valiosos derechos colectivos.

Este trabajo se propuso explicar esta paradoja. La fragmentación se explica porque la EOP generó incentivos para que los movimientos privilegiaran en un primer momento el repertorio institucional-electoral, lo cual tuvo consecuencias paradójicas: al mismo tiempo provocó la competencia electoral entre fracciones del movimiento katarista y permitió el establecimiento de alianzas con las élites gubernamentales del MNR para llevar a cabo las reformas de 1994. Aunque en términos generales los movimientos no pudieron generar una articulación estable y orgánica, supieron aprovechar oportunidades políticas en coyunturas particulares combinando distintos repertorios, estableciendo alianzas con actores influyentes y creando sus propias oportunidades. Es decir, este caso permite afirmar que las dinámicas de la acción colectiva se producen en una compleja dialéctica entre las oportunidades y constricciones estructurales y la agencia de los actores sociales y políticos.

La «democracia pactada» ofreció incentivos para la participación institucional de los movimientos indígenas, mientras una tradición de represión aumentaba los costos para la acción colectiva de protesta. Ello hizo posible que un sector de los movimientos encontrara aliados influyentes, en este caso el MNR de Sánchez de Lozada, para llevar a cabo las reformas en 1994. Por otra parte, los cambios en las EOP con el derrumbe de la «democracia pactada» alentaron la protesta pese a los costos en términos de represión en Bolivia, entre 2000 y 2005.

Este análisis permite matizar ciertas asunciones comunes en el estudio de los movimientos sociales.
Desde la perspectiva del impacto institucional de la acción colectiva, la fuerza de un movimiento social no siempre depende de su cohesión organizativa y discursiva, ni de su capacidad para generar protestas de gran alcance. Así, un movimiento indígena «débil» pudo conseguir el reconocimiento de sus derechos colectivos en forma temprana y sin mucha conflictividad al encontrar aliados influyentes entre las élites políticas y privilegiar un repertorio de protesta institucional, pese a su fragmentación organizativa y discursiva. Es necesario realizar análisis más matizados de la «fortaleza» 0 «debilidad» de los movimientos enfocando dimensiones como el contexto político y los tipos de repertorios implementados.

De la misma manera, no siempre los estados represivos inhiben las posibilidades de realización de los objetivos de los movimientos. Un Estado represivo como el boliviano permitió la realización de ciertos objetivos de los movimientos indígenas en forma temprana. En estos casos, factores como la apertura de los canales institucionales, el grado de legitimidad del Estado o la forma como los movimientos construyen sus oportunidades pueden tener mayor capacidad explicativa.

\section{Referencias bibliográficas}

Albó, Xavier. «Bases étnicas y sociales para la participación aymara». En: Calderón Fernando y Dandler Jorge (Comps.), Bolivia: la fuerza histórica del campesinado. Ginebra: UNRISD-CERES, pp. 401-442, 1986.

Albó, Xavier«De Mnristas a Kataristas a Katari». En: Stern Steve J. (Comp.), Resistencia, rebelión y conciencia campesina en los Andes. Siglos XVIII al XX. Lima, IEP, pp. 357-389, 1990.

Albó, Xavier. «Nación de muchas naciones: nuevas corrientes políticas en Bolivia». En: González Casanova Pablo y Roitman Rosenman Marcos (Eds.), Democracia y Estado multiétnico en América Latina. México: Centro de Investigaciones Interdisciplinarias en Ciencias y Humanidades -UNAM- La Jornada Ediciones, pp. 321-366, 1996.

Albó, Xavier. «Derechos indígenas indios en Bolivia. Lectura desde el Borrador de Consulta de la OEA sobre los derechos de los pueblos indígenas». En: Almeida lleana y Arrobo Rodas Nidia (Coords.). En defensa del pluralismo y la igualdad. Los derechos de los pueblos in- 
dios y el Estado. Quito: Fundación Pueblo Indio del Ecuador-Abya Yala, pp. 11-33, 1998.

Albó, Xavier. «Retornando a la solidaridad y faccionalismo aymara». En: Lair Eric y Sánchez Gonzalo (Eds.), Violencias y estrategias colectivas en la región andina. Bolivia, Colombia, Ecuador, Perú y Venezuela. Bogotá: Norma-IFEA-IEPRI, pp. 444-484, 2004.

Andolina, Robert; Racliffe, Sarah y Lawrie, Nina. «Gobernabilidad e identidad: indigeneidades transnacionales en Bolivia». En: Dávalos Pablo (Comp.). Pueblos indígenas, Estado y democracia. Buenos Aires: Clacso, pp. 133-170, 2005.

Archondo, Rafael. «La ruta de Evo Morales». En: Nueva Sociedad. No 209, mayo-junio, pp. 82-99, 2007.

Arias Durán, Iván y Molina, Sergio. «De la nación clandestina a la participación popular». En: República de Bolivia-Ministerio de Desarrollo Humano-Secretaría Nacional de Participación Popular, El pulso de la democracia. Participación ciudadana y descentralización en Bolivia. Caracas: Nueva Sociedad, pp. 59-74, 1997.

Arnold, Denise Y., y Spedding P. Alison. «Género, etnicidad y clases sociales: la mujer en los movimientos sociales y movimientos de mujeres». En: Iglesias Turrión Pablo y Espasandín López Jesús (Coords.). Bolivia en movimiento. Acción colectiva y poder político. España: El Viejo Topo, pp. 155-188, 2007.

Balza Alarcón, Roberto. Tierra, territorio y territorialidad indígena. Un estudio antropológico sobre la evolución en las formas de ocupación del espacio del pueblo indígena chiquitano de la ex reducción jesuita de San José. Santa Cruz de la Sierra: APCOB-SNU-IWGIA, 2001.

Basset, Yann. «El derrumbe del modelo boliviano de gobernabilidad». En: Análisis Político. Núm. 51, mayo agosto, pp. 51-63, 2004.

Basset, Yann. «Bolivia en la tormenta. Algunas consideraciones sobre la crisis social». En: Oasis. No. 11, pp. 189-212, 2005.

Bengoa, José. La emergencia indígena en América Latina. Santiago de Chile: FCE, 2000.

Cabezas, Marta. «Caracterización del «ciclo rebelde» 2000-2005». En: Iglesias Turrión Pablo y Espasandín Ló- pez Jesús (Coords.), Bolivia en movimiento. Acción colectiva y poder político. España: El Viejo Topo, pp. 189-219, 2007.

Cajías de la Vega, Magdalena. «Rebelión y negociación en el mundo aymara boliviano». En: Lair Eric y Sánchez Gonzalo (Eds.). Violencias y estrategias colectivas en la región andina. Bolivia, Colombia, Ecuador, Perú y Venezuela. Bogotá: Norma-IFEA-IEPRI, pp. 485514, 2004.

Calla Ortega, Ricardo. "Identificación étnica y procesos políticos en Bolivia (1973-1991)». En: VVAA, Democracia, etnicidad y violencia política en los países andinos. Lima: IFEA-IEP, pp. 57-81, 1993.

De la Fuente, Manuel. «Del reino del neoliberalismo a la insurgencia de los indígenas y campesinos. La posibilidad de construir una nueva Bolivia». En: OSAL. No. 8, septiembre, pp. 83-88, 2002.

della Porta, Donatella. «Movimientos sociales y Estado: algunas ideas en torno a la represión policial de la protesta». En: McAdam Doug, McCarthy John D. y Zald Mayer N., Movimientos sociales: perspectivas comparadas. Oportunidades políticas, estructuras de movilización y marcos interpretativos culturales. Madrid: Itsmo, pp. 100-142, 1999.

Do Alto, Hervé. «El MAS-IPSP boliviano, entre movimiento social y partido político». En: Análisis Político. № 62, enero-abril, pp. 25-43, 2008.

Gamson, William A. y Meyer, David S. «Marcos interpretativos de la oportunidad política». En: McAdam Doug, McCarthy John D. y Zald Mayer N., Movimientos sociales: perspectivas comparadas. Oportunidades politicas, estructuras de movilización y marcos interpretativos culturales. Madrid: Itsmo, pp. 389-412, 1999.

García, Fernando. «Política, Estado y diversidad cultural: a propósito del movimiento indígena ecuatoriano». En: Bretón Víctor y García Francisco (Eds.), Estado, etnicidad y movimientos sociales en América Latina. Ecuador en crisis. Barcelona: Icaria, pp. 193-215, 2003.

Gros, Christian. «Ser diferente por (para) ser moderno 0 las paradojas de la identidad. Algunas reflexiones sobre la construcción de una nueva frontera étnica en América Latina». En: Análisis Político. No. 36, enero- abril, pp. 320, 1999. 
Gros Christian. «De la nación mestiza a la nación plural: el nuevo discurso de las identidades en el contexto de la globalización». En: Sánchez Gonzalo y Wills Maria Emma (Comps.), Museo, memoria y nación. Misión de los museos nacionales para los ciudadanos del futuro. Bogotá: ICANHIEPRI-Ministerio de Cultura, pp. 351-363, 2000.

Hirsch Silvia María. «The emergence of political organizations among the Guaraní Indians of Bolivia and Argentina: A comparative perspective». En: Langer Erick y Muñoz Elena (Eds.). Contemporary indigenous movements in Latin America. Washington: Scholary Books, pp. 81-101, 2003.

Ibarra Hernán. «Intelectuales indígenas, neoindigenismo e indianismo en el Ecuador». En: Ecuador Debate. No 48, diciembre, pp. 71-94, 1999.

Iglesias Turrión, Pablo y Espasandín López, Jesús. «Introducción. La globalización y los movimientos sociales bolivianos». En: Iglesias Turrión Pablo y Espasandín López Jesús (Coords.). Bolivia en movimiento. Acción colectiva y poder político. España: El Viejo Topo, pp. 29-65, 2007.

Martí i Puig, Salvador. «Después de la «década de los pueblos indígenas» ¿qué? El impacto de los movimientos indígenas en las arenas políticas de América Latina». En: Nueva Sociedad. No 227, mayo-junio, pp. 68-82, 2010.

McAdam Doug, McCarthy John D. y Zald Mayer N. «Oportunidades, estructuras de movilización y procesos enmarcadores: hacia una perspectiva sintética y comparada de los movimientos sociales». En: McAdam Doug, McCarthy John D. y Zald Mayer N., Movimientos sociales: perspectivas comparadas. Oportunidades politicas, estructuras de movilización y marcos interpretativos culturales. Madrid: Itsmo, pp. 21-46, 1999.

McAdam, Doug. «Orígenes terminológicos, problemas actuales, futuras líneas de investigación». En: Movimientos sociales: perspectivas comparadas. Oportunidades políticas, estructuras de movilización y marcos interpretativos culturales. Doug McAdam, Jhon McCarthy y Mayer Zald (Eds.): 49-70. Madrid: Itsmo, 1999.

McAdam, Doug, Sidney Tarrow y Charles Tilly. Dinámica de la contienda política. Barcelona: Hacer , 2005.

McCarthy John D. «Adoptar, adaptar e inventar límites y oportunidades». En: McAdam Doug, McCarthy John D. y Zald Mayer N., Movimientos sociales: perspectivas comparadas. Oportunidades políticas, estructuras de movilización y marcos interpretativos culturales. Madrid: Itsmo, pp. 205-220, 1999.

Oberschall, Anthony. «Oportunidades y creación de marcos en las revueltas de 1989 en el Este de Europa». En: McAdam Doug, McCarthy John D. y Zald Mayer N., Movimientos sociales: perspectivas comparadas. Oportunidades políticas, estructuras de movilización y marcos interpretativos culturales. Madrid: Itsmo, 1999 [1996] pp. 143-181, 1999.

Orellana, René. «Asamblea constituyente. Inventario de protestas campesino indígenas, sus características y procedimientos». En: León, Jorge (Ed.). Participación política, democracia y movimientos indígenas en los andes. La Paz, IFEA-Embajada de Francia en Bolivia-PIEB, pp. 53-73, 2005.

Pearse, Andrew. «Campesinado y revolución: el caso de Bolivia». En: Calderón Fernando y Dandler Jorge (Comps). Bolivia: la fuerza histórica del campesinado. Ginebra: UNRISD-CERES, pp. 313-361, 1986.

Pessoa, Vicente. «Procesos indígenas de participación política y ciudadanía en los espacios de gobierno y desarrollo municipal». En: V. Alta; D. Iturralde y M. A. LópezBassols (Comps.), Pueblos indígenas y Estado en América Latina. Quito, Universidad Andina Simón Bolívar: Abya Yala, pp. 169-203, 1998.

Rivas, Antonio. «El análisis de los marcos: una metodología para el estudio de los movimientos sociales», en Ibarra Pedro y Tejerina Banjamín (eds.) Los movimientos sociales. Transformaciones políticas y cambio cultural. Madrid: Trotta, pp. 181-215, 1998.

Rivera Cusicanqui, Silvia. Oprimidos pero no vencidos. Luchas del campesinado aymara y quechua de Bolivia 1900-1980. Ginebra: UNRISD, 1986.

Ruch, Dieter. «El impacto de los contextos nacionales sobre la estructura de los movimientos sociales: un estudio comparado transnacional y entre movimientos». En: McAdam Doug, McCarthy John D. y Zald Mayer N., Movimientos sociales: perspectivas comparadas. Oportunidades políticas, estructuras de movilización y marcos interpretativos culturales. Madrid: Itsmo, pp. 262-287, 1999. 
Sanz Galindo, Camilo. «Discurso y poder en la re-construcción de estrategias contestatarias en el movimiento cocalero boliviano desde una perspectiva comparativa con el caso peruano. La heterogeneidad y ambigüedad como plataformas articulatorias de una acción colectiva eficaz»». En: Documentos CESO, No. 91, Bogotá: Universidad de los Andes, 2005.

Snow, David A. y Benford, Robert D. «Master frames and cycles of protest». En: Morris Aldon D. y McClury Mueller Carol, 1992. Frontiers in social movement theory. New Haven and London: Yale University Press, pp. 133155, 1992.

Stefanoni, Pablo y Do Alto, Hervé. La revolución de Evo Morales. De la coca al palacio. Buenos Aires: Capital Intelectual, 2006.

Tarrow Sidney. El poder en movimiento. Los movimientos sociales, la acción colectiva y la política. Madrid: Alianza, 1997.

Tarrow Sidney.«Estado y oportunidades: la estructuración política de los movimientos sociales». En: McAdam Doug, McCarthy John D. y Zald Mayer N., Movimientos sociales: perspectivas comparadas. Oportunidades políticas, estructuras de movilización y marcos interpretativos culturales. Madrid: Itsmo pp. 71-99, 1999.

Ticona Alejo, Esteban. «Pueblos indígenas y Estado boliviano. Una aproximación a sus relaciones desde la cúpula de la CSUTCB». En: León, Jorge (Ed.). Participación política, democracia y movimientos indígenas en los andes. La paz, IFEA-Embajada de Francia en Bolivia-PIEB, pp. 147-160, 2005.
Torrico Terán, Mario. "Qué ocurrió realmente en Bolivia». En: Perfiles Latinoamericanos. No. 28, juliodiciembre, pp. 231-261, 2006.

Vadillo Alcides. "Constituciones y comunidades indígenas en Bolivia». En: Sánchez Enrique (Comp.), Derechos de los pueblos indígenas en las Constituciones de América Latina. Memorias del seminario internacional de expertos sobre régimen constitucional y pueblos indígenas en países de Latinoamérica. Bogotá: Disloque Editores, pp. 22-31, 1996.

Van Cott, Donna Lee. «Cambio Institucional y partidos étnicos en Suramérica». En: Análisis Político. No. 48, enero-abril, pp. 26-51, 2003.

VVAA. Historia, coyuntura y descolonización. Katarismo e indianismo en el proceso político del MAS en Bolivia. La Paz: Fondo Editorial Pukara, 2010.

Zald Mayer N. «Cultura, ideología y creación de marcos estratégicos». En: McAdam Doug, McCarthy John D. y Zald Mayer N., Movimientos sociales: perspectivas comparadas. Oportunidades políticas, estructuras de movilización y marcos interpretativos culturales. Madrid: Itsmo, pp. 369-388, 1999.

Zalles Cueto, Alberto. «Bolivia: hundimiento de la Asamblea Constituyente y naufragio del proyecto de Constitución», en Íconos revista de ciencias sociales, №. 32, sep., pp. 145-153, 2008.

Zuazo, Moira. «¿Los movimientos sociales en el poder? El gobierno del MAS en Bolivia». En: Nueva Sociedad. No. 227, mayo-junio, pp. 120-135, 2010. 